\title{
SIGNIFICANCE OF N95 MASKS IN THE PANDEMIC
}

\author{
Manav Gupta ${ }^{\mathrm{a}}$ \\ aupta.manav905@gmail.com \\ Christ University Master of Business Administration \\ Mysore Road, Kumbalgodu, Karnataka-560074 \\ India
}

\begin{abstract}
The year 2020 has known to be a year of disaster for mankind. From natural calamities to coronavirus disease, the world is trying to find its way to fight back. WHO announced the COVID-19 outbreak as a pandemic in March 2020. The COVID19 statistics show that 16.5 (approx.) million people have been affected by this virus and 654K people lost their lives all over the world by July 2020. In the current scenario, the emergent need for countries all over the world is to stop the spread of coronavirus disease. The objectives of this paper are- 1 . To form a roadmap to be followed which could help to fight coronavirus disease 2. To explain the advantage of the N95 mask over the other masks. This paper puts light on the significance of N95 masks to hinder the spread of coronavirus. This research is useful for the people around all over the globe who are not using proper precautions for this situation which could help save humanity in this period. Various interviews were conducted to know the perception of people with respect to the N95 mask. The critical analysis made by the study is that not many people are aware of the significant aspects of N95 mask concerning coronavirus disease.
\end{abstract}

Keywords: coronavirus disease, N95 mask, pandemic

\section{Introduction}

We are facing a pandemic situation right now which we never imagined could be possible. Originated in Wuhan, China when the first case of Coronavirus was identified on November $17^{\text {th }}, 2019$ and it has spread worldwide (Zhi, 2020). In India, the first COVID-19 case was identified on $30^{\text {th }}$ January 2020. It has been several months since we are dealing with this situation and trying to fight back every day dealing with a lot of problems. It could be well said that the poor people of the country are most affected by this situation as they have many big savings in their account which they could utilize to fulfil their basic needs. Migrant laborers are also majorly affected by this situation. Away from their homes without any source of income, they are facing problems that could disturb them financially, mentally as well as physically. This research is based on how we could fight back coronavirus with the help of a few precautions. One of the most important precautions is to cover your face with a mask to protect yourself from COVID-19. But people are not using the proper prescribed mask to cover their faces. They are using normal cloth and other normal mask which have very limited period of usage. The most effective mask in fighting back COVID-19 is N95 mask (Jessica J. Bartoszko1 | Mohammed Abdul Malik Farooqi2 | Waleed Alhazzani1, 2020). This research is used to provide insights to the people who are not aware of the right precautions to be followed for preventing COVID-19. Interviews of people of different ages have been recorded to gather information about their views on covid-19 and N95 mask. Efforts are to identify the perception of the people for not using N95 mask and provide suitable arguments in favour of using the mask. As covering your face with the help of mask is the primary precaution which everyone must follow (Cascella M, 2020). Some provinces and municipalities located in China have enforced compulsory face mask policies in for the public; however, China's national guideline has adopted a risk-based approach in offering recommendations in order to use face masks among health-care workers and the general public (Feng S, 2020). This research studies the people's perception and relates it with the Howard Sheth Model of consumer behavior.

COVID-19 is often more prone to following- 
- People who are older than 60 years

- People who have health conditions like lungs, heart disease, diabetes or conditions that affect their immune system

\section{Problem Definition}

- To provide solution on how to fight COVID-19

- To educate about the use of N95 mask in regard of COVID-19

\section{SCOPE OF RESEARCH}

This research is based on the pandemic situation which whole world is facing right now and trying to fight back each and every day. This research highlights the importance of N95 masks in this current situation of pandemic. This research is useful for the people around all over the globe who are not using proper precautions for this situation which could help save humanity in this period. With the help of this study more awareness could be spread about how N95 mask is different and more effective than other masks in this pandemic.

\section{OBJECTIVES OF THE RESEARCH}

- To form a roadmap to be followed which could help people to fight COVID-19

- To explain the advantages of N95 mask over the other masks

\section{Theoretical Framework}

A N95 mask is a particulate-sifting facepiece respirator that encounters the necessities for U.S. National Institute for Occupational Safety and Health (NIOSH) N95 characterization of air filtration. This implies that it can channel in any event $95 \%$ of airborne particles. This particular kind is recognized as the most widely recognized particulate-separating face respirator. Also, known as the case of the mechanical channel respirator, which gives security against particulates yet not against gases or fumes about all specialists suggest that medicinal services laborers wear a N95 cover or proportionate gear while playing out a vaporized creating technique (Ng K, 2020)

Across the board, utilization of suggested obstruction safety measures, (for example, covers, gloves, outfits, and eye wear) under the watchful eye of all patients with respiratory indications must be of most elevated need (Adams JG, 2020). N95 respirators are viewed as practically equal as regard to specific respirators directed under the non-U.S. purviews. Notwithstanding, somewhat various models are utilized to grandstand their presentation, for example, test specialist and stream rate, the channel proficiency, and admissible weight drop. The N95 cover requires a fine work of manufactured polymer filaments. It is delivered by dissolve blowing and structures the inward filtration coating that can sift through perilous particles.

A N95 cover, when fitted accurately, squares $95 \%$ of 0.3 -micron particles, and gives a significant hindrance against malady transmission as a feature of a medicinal services supplier's very own defensive hardware known as personal protective equipment(PPE) (Cramer, 2020). The N95 respirator mask is progressively being utilized for hindering the COVID-19 spread over the world. The N95 masks is known for as much more close fitting contrasted with the other expendable careful masks (Samy Rengasamy B. C., 2014). They can channel up to $95 \%$ of little particles including microscopic organisms and infections. Aside from going about as a boundary to enormous beads, showers, sprinkles, the N95 respirator masks have a few different focal points:

- Protects against breathing in dust, smoke, fog.

- Protects against tainting of infections, for example, COVID-19.

- Can channel particles of up to 0.3 microns or bigger. 
- Can be reused in the wake of washing.

About COVID-19

Coronavirus 2019 (COVID-19) is an irresistible illness brought about by the serious intense respiratory condition. The table below shows the place of origin of the virus in different countries along with the period in which the first positive case was affirmed in the respective country.

Table 1. Origin of COVID-19

\begin{tabular}{lll}
\hline Place & Country & First Positive Case \\
\hline Hubei University, Wuhan & China & December 2019 \\
Turin and Milan & Italy & December 2019 \\
Kerala & India & January 30, 2020 \\
Barcelona & Spain & March 12, 2020 \\
\hline
\end{tabular}

Normal side effects incorporate hack, fever, windedness, exhaustion, and loss of smell and taste. While most of cases bring about gentle manifestations, some advance to intense respiratory misery condition. The interval between presentations to appearing of manifestations is regularly less than a week. The infection is basically spread between individuals that are in proximity to each other, regularly by little beads delivered by sniffling, talking and hacking. The beads for the most part tumble to the surface or onto ground instead of going through air over the significant distances. In any case, research as of June 2020 has indicated that the discourse produced beads may stay airborne for inexact many minutes. Less ordinarily, individuals may get tainted by contacting the defiled surface and afterward contacting their face.

The table given below shows the statistics of the countries with leading number of corona cases. The record mentioned in the table is taken from the source (https://www.worldometers.info/coronavirus/) updated on 26 August, 2020.

Table 2. COVID-19 Statistics

\begin{tabular}{llll}
\hline Country & Cases & Deaths & Recovered \\
\hline USA & $5,944,922$ & 182,043 & $3,232,670$ \\
Brazil & $3,231,522$ & 115646 & $2,778,709$ \\
India & $3,231,522$ & 59,608 & $2,467,220$ \\
\hline
\end{tabular}

COVID-19 in India

On 11 March 2020, WHO declared Novel Coronavirus Disease (COVID-19) outbreak as a pandemic and made the call for countries to take immediate appropriate actions and scale up response to treat, detect and reduce transmission in order to save people's lives. 
On 24th March, 2020, Prime Minister Narendra Modi requested an across the nation lockdown for 21 days, known as Janta curfew constraining development of the whole 1.3 billion populace of India so as to forestall the spread of the COVID-19 pandemic in India(P., 2020). It was ordered following a 14-hour willful open time limitation on 22 March, trailed by the requirement of arrangement of guidelines in the nation's coronavirus influenced locales. The lockdown was put when the quantity of affirmed positive coronavirus cases in India was roughly 500. Spectators have expressed that the lockdown had come about to eased back the development pace of the pandemic by 6 April to a pace of multiplying like clockwork, and by 18 April, to a pace of multiplying after like clockwork.As the end of the first lockdown period approached, state governments and other committees recommended extending the lockdown.

Still till July, in places like NCT of Delhi, Tamil Nadu, Maharashtra and many more, COVID-19 cases are increasing day by day. Total confirmed Cases in Maharashtra are 180298+ in which 93000+ have been recovered. We can see India has a recovery rate of $60.70 \%$ which is generally good as compared to other countries.

\section{Methodology}

Primary data would be collected from interviews of different aged groups trying to record their perception about the N95 mask in regard in COVID-19. Effort has been put to gather insights regarding the use of mask in order to protect yourself from the virus in this pandemic. Another source of data is online reviews which people have put after purchasing the N95 mask online through online websites such as Amazon.

Table 3. Selected Responses

\begin{tabular}{|c|c|c|c|}
\hline Age & $\begin{array}{l}\text { Have they ever used N95 } \\
\text { mask }\end{array}$ & $\begin{array}{c}\text { Whether they are aware of the advantages of N95 } \\
\text { mask against COVID-19 }\end{array}$ & $\begin{array}{c}\text { Their reviews about the } \\
\text { mask }\end{array}$ \\
\hline 16 & YES & YES & Good quality \\
\hline 22 & YES & YES & Feel safe \\
\hline 24 & YES & YES & Good and comfortable \\
\hline 21 & YES & YES & $\begin{array}{l}\text { Good and cautious about } \\
\text { (UVID-1Y }\end{array}$ \\
\hline 38 & $\mathrm{NO}$ & NO & $\begin{array}{c}\text { Think could use another } \\
\text { normal mask as it is } \\
\text { costly }\end{array}$ \\
\hline 30 & YES & PARTIALLY & Doctor recommendation \\
\hline 32 & $\mathrm{NO}$ & PARTIALLY & Costly \\
\hline 28 & YES & YES & Good and comfortable \\
\hline
\end{tabular}

The table 3 shows selected responses amongst various responses collected by interview taken about the perception of N95 mask in regard of Corona virus disease.

Analysis Table

Various interviews were taken in regard to capture the perception and mind-set of the consumers using or not using N95 mask in context of Corona virus disease. Various research paper has been referred in order to come at a conclusion on how we can fight back COVID-19. Such research works are analyzed in the table given below.

Table 4. Research Analysis 


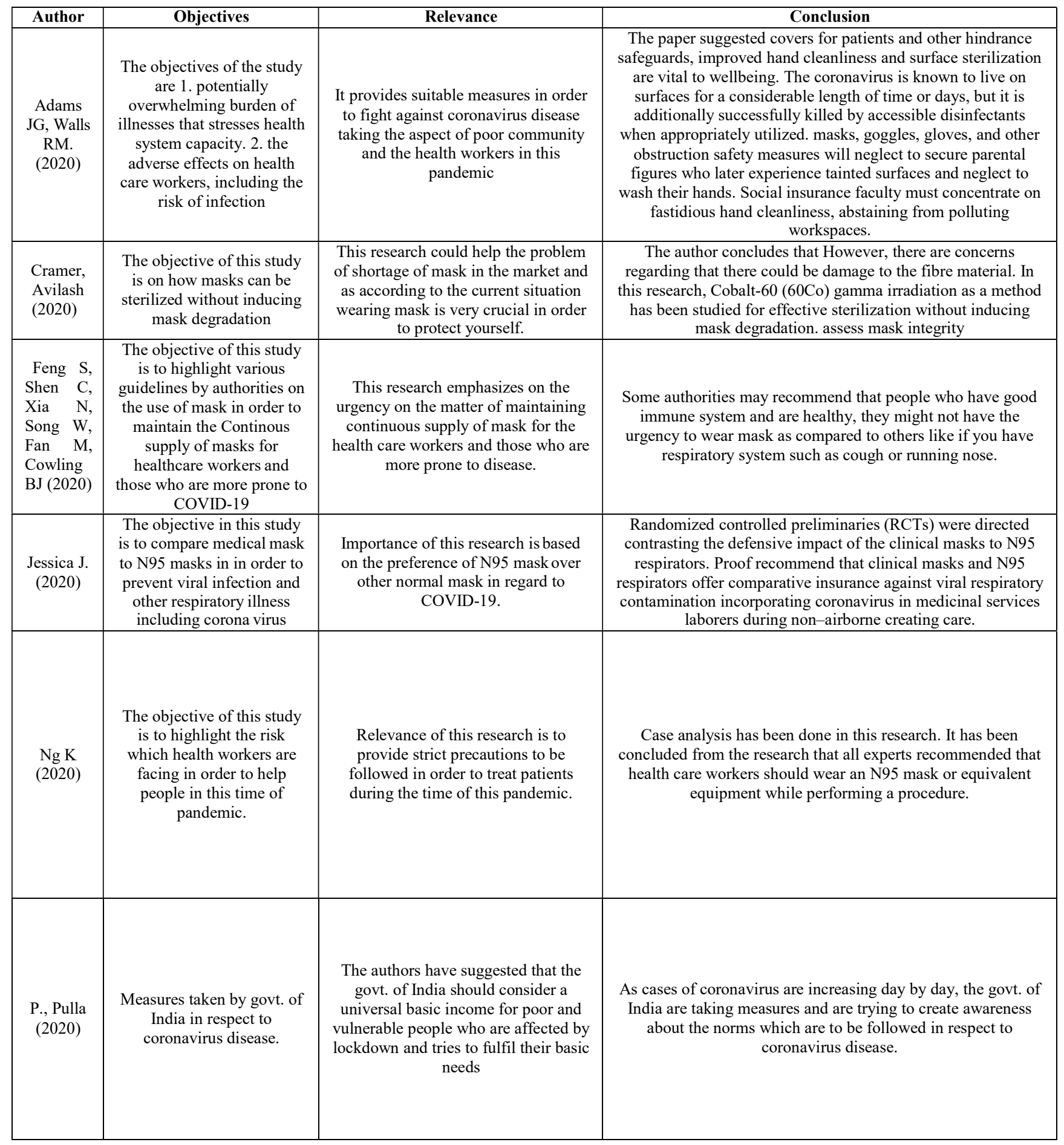




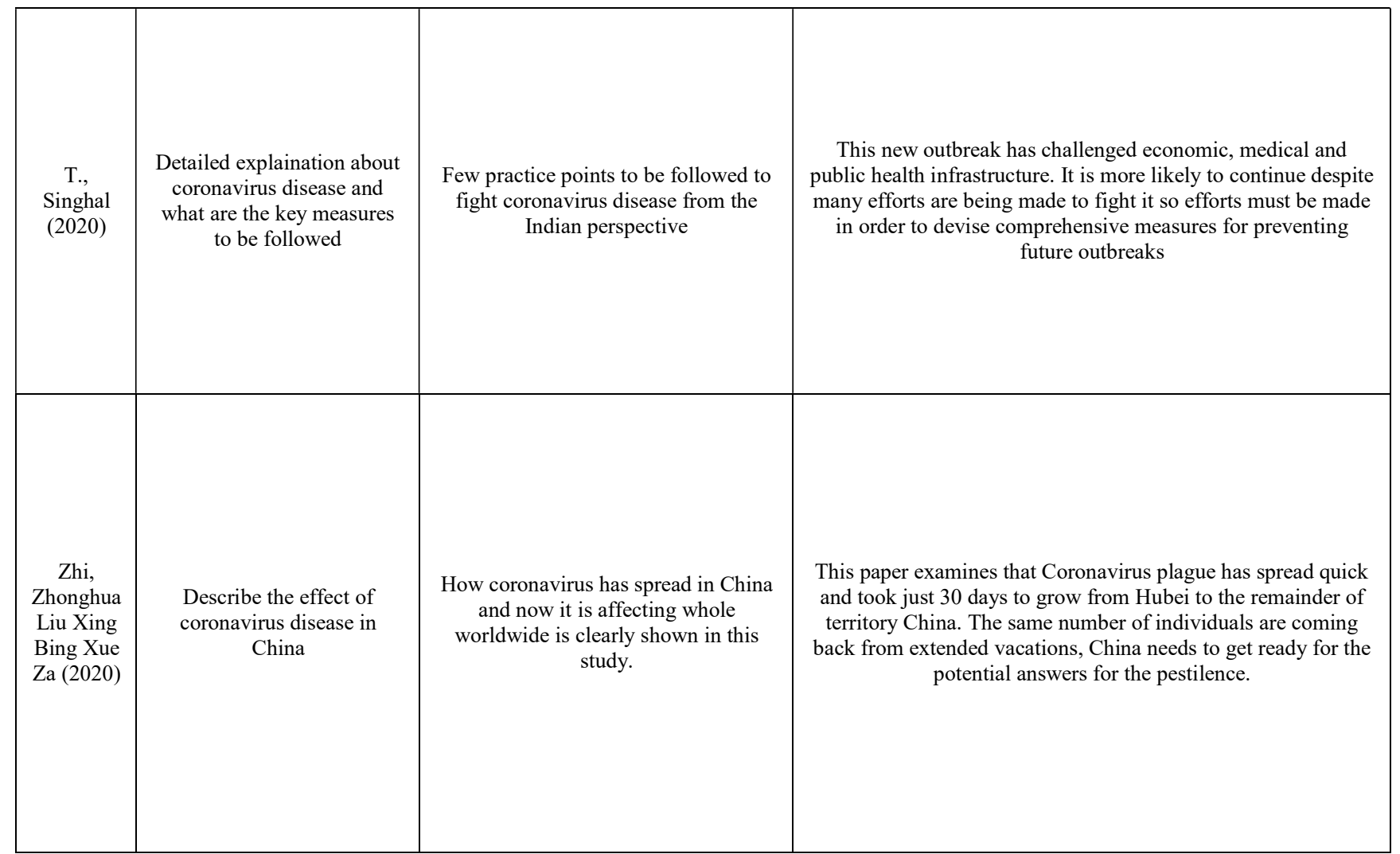

ROADMAP-A roadmap has been made in order to describe the norms to be followed in order to fight back corona virus disease. It shows few MUST DO things (J., 2020) in this time of pandemic-

- Wear N95 mask or other approved mask to cover your face

- Follow the norms of social distancing

- Avoid going to crowded places

- Keep your hand sanitized

- $\quad$ Try to build good immune system by having proper diet and doing normal exercises

\section{ADVANTAGES OF N95 OVER OTHER MASKS}

Many consumers don't know all of the benefits that N95 mask provides in order to fight Corona virus disease. Many people use normal mask for a longer duration of time and they are not aware of the fact that those normal masks come with an expiry date and are preferred only for a particular period of time. Other masks are not able to cover the face properly as they might not able to provide a tight fitting on the face in order to prevent germs to get in contact of the person. Not at all like NIOSH-endorsed N95s, different facemasks are baggy and give just hindrance security against beads, including enormous respiratory particles (J.L. Derrick, 2005). No fit testing or seal check are required with facemasks. Most facemasks don't work 
viably so as to channel little particles from the air and don't forestall spillage around the edge of mask when the individual breathes in(Samy Rengasamy B. E., 2010). Following are the few benefits of N95 mask which make it more distinctive from other masks which could help to fight corona virus disease-

- N95 respirators decrease the client's presentation to airborne particles, from little molecule pressurized canned products to enormous beads.(Smith JD, 2016) N95 respirators are known as tight-fitting respirators that filter out at least $95 \%$ of the particles in air, including large and small particles.

- N95 masks are tested, evaluated, and approved by NIOSH as per the requirements.

- Reduces user's exposure to particles including large droplets and small particle aerosols.

- It has a tight fitting and comfortable to wear

As wearing N95 mask only doesn't guarantee you a protection against COVID-19 as it is very important that you are wearing that mask properly and follow some norms in order to ensure that there is maximum possibility that you are protected from corona virus (Cowling BJ, 2010). There are few norms which are to be strictly followed like-

- While going out to eat something or at some other place other than home you must wear mask.

- When you are about to eat something, you must remove your mask.

- This is why many people pull down their mask on their neck which is wrong because there is already exposed to the germs which are harmful for our health.

- When they again use that mask in order to cover their face, it would be already contaminated as there was a contact with the inner part of mask with the neck of the person.

\section{Implications and Contribution to Knowledge}

This research emphasizes on the role of N95 mask played in fighting the pandemic of Corona virus disease. Importance of N95 mask has been highlighted in this research.

- Practical Implications- The findings of this research are useful for the people who are more prone to COVID-19 as they have to take special care in respect to this pandemic situation. They includepeople who are older than 60 years old and people who have health conditions like lungs, heart disease, diabetes or conditions that affect their immune system. They could follow the proper norms for the prevention of the corona virus disease.

- Theoretical Implications- This research will create a basis for further studies those who want to do research on importance of N95 masks and how it can help to prevent the spread of Corona virus disease. This research could also help in future if any other similar pandemic people face. This would help people to be prepared in advance to fight back the pandemic situation like corona virus disease

\section{MANAGERIAL RECOMMENDATIONS TO THE BRANDING TEAM}

It is clear that N95 mask plays a very crucial part in fighting back corona virus disease by covering the face with its protective shield. But somehow, we don't see that everyone has been using N95 mask due to some reason. It could be due to price factor, availability issue or many other reasons. There are few managerial recommendations to the branding team: 
- Proper awareness must be done in order to educate people about how N95 mask is more effective than other masks. TV advertisements could also be done in order to educate people,

- Make sure there is availability of N95 mask in every market to every customer. It is important to ensure that there is no shortage of the product in the market.

- The price factor is important issue for many customers as N95 mask starts from Rs.150 and it is not affordable for every lower- and middle-class people to afford it. They can reduce the price by substituting lower cost materials where ever possible and not compromising with the quality.

\section{Machine Learning Techniques for Future Research}

In future, we aim to employ machine learning techniques for the predicting the correlation between awareness among people and the spread of corona virus. The attributes that will be considered during the construction of the computational model based on machine learning will be whether the person tested positive wore $\mathbf{N 9 5}$ mask or other approved mask to cover themselves, followed social distancing norms, attended some crowded gathering, used hand sanitized or has good immune system. This can evidently point the requirement of awareness among people of safety measures.

\section{Conclusion}

The cases of coronavirus disease are increasing day by day at a rapid rate which is creating a challenge as economic as well as health for the whole world. There is a need to take proper measures in order to fight coronavirus. The roadmap to be followed for fighting coronavirus disease could be as -Wear N95 mask or other approved mask to cover your face, Follow the norms of social distancing, avoid going to crowded places, keep your hand sanitized, try to build good immune system by having proper diet and doing normal exercises. The role of N95 mask in fighting coronavirus disease is very crucial as it has been cleared that N95 mask is more superior in terms to avoid respiratory infections transmitting through persons. N95 respirators reduce the user's exposure to airborne particle so as to provide protection against various disease specially coronavirus. Although there are still some strict ways to be followed while wearing N95 mask so that maximum protection could be provided against coronavirus disease.

\section{References}

Adams JG, W. R. (2020). Supporting the Health Care Workforce During the COVID-19 Global Epidemic. JAMA. doi:10.1001/jama.2020.3972

Cascella M, R. M. (2020). Features, Evaluation and Treatment Coronavirus (COVID-19). StatPearls Publishing.

Cowling BJ, Z. Y. (2010). Face masks to prevent transmission of influenza virus: a systematic review. Epidemiology and Infection., 138(4), 449-456. doi:10.1017/s0950268809991658

Cramer, A. (2020). DISPOSABLE N95 MASKS PASS QUALITATIVE FIT-TEST BUT HAVE DECREASED. doi: https://doi.org/10.1101/2020.03.28.20043471

Feng S, S. C. (2020). Rational use of face masks in the COVID-19 pandemic. Lancet Respir Med., 8(5), 434-436. doi:10.1016/S22132600(20)30134-X

J., W. (2020). Preventing a covid-19 pandemic. BMJ. Clinical Research ed. doi:10.1136/bmj.m810

J.L. Derrick, C. G. (2005). Protecting healthcare staff from severe acute respiratory syndrome: filtration capacity of multiple surgical masks. Journal of hospital infection, 59(4), 365-368. doi:https://doi.org/10.1016/j.jhin.2004.10.013

Jessica J. Bartoszko1 | Mohammed Abdul Malik Farooqi2 | Waleed Alhazzani1, 3. |. (2020). Medical masks vs N95 respirators for preventing COVID-19 in. Influenza Other Respir Viruses, 14(4), 365-373. doi:10.1111/irv.12745

Ng K, P. B. (2020). COVID-19 and the Risk to Health Care Workers: A Case Report. Ann Intern Med., 172(11), 766-767. doi:10.7326/L20-0175

P., P. (2020). Covid-19: India imposes lockdown for 21 days and cases rise. BMJ., 368:m1251. doi:10.1136/bmj.m1251 
Samy Rengasamy, B. C. (2014). A Quantitative Assessment of the Total Inward leakage of f NaCl Aerosol Representing SubmicronSize Bioaerosol Through N95 Filtering Facepiece Respirators and Surgical Masks. Journal of Occupational and Environmental Hygiene, 11(6), 388-396,. doi:10.1080/15459624.2013.866715

Samy Rengasamy, B. E. (2010). Simple Respiratory Protection-Evaluation of the Filtration Performance of Cloth Masks and Common Fabric Materials Against 20-1000 nm Size Particles. The Annals of Occupational Hygiene, 54(7), 789-798. doi:https://doi.org/10.1093/annhyg/meq044

Smith JD, M. C. (2016). Effectiveness of N95 respirators versus surgical masks in protecting health care workers from acute respiratory infection: a systematic review and meta-analysis. 188(8), 567-574. doi:10.1503/cmaj.150835

T., S. (2020). A Review of Coronavirus Disease-2019 (COVID-19). Indian J Pediatr., 87(4), 281-286. doi:10.1007/s12098-020-03263-6

Zhi, Z. L. (2020). The epidemiological characteristics of an outbreak of 2019 novel coronavirus diseases (COVID-19) in China. Chinese Center for Disease Control and Prevention, 41(2), 145-151. doi:10.3760/cma.j.issn.0254-6450.2020.02.003 